\title{
Challenges to Aligning Coordination Technology with Organizations, People, and Processes in Healthcare
}

\author{
Susan A. Sherer \\ Lehigh University \\ sas6@lehigh.edu
}

\author{
Chad D. Meyerhoefer \\ Lehigh University \\ chm308@1ehigh.edu
}

\author{
Donald Levick \\ Lehigh Valley Health Network \\ Donald.Levick@1vhn.org
}

\begin{abstract}
Healthcare coordination has proven difficult to achieve, even with new coordination technologies such as shared electronic health records. Successful coordination requires alignment of information technology with new organizational structures, reskilled personnel, and reengineering of work processes. We suggest that this is more challenging in the healthcare industry as a result of the need for integrating information across care cycles, payment and regulatory mechanisms, high degree of professional control, failure impact and privacy concerns, and information granularity across the care cycle. We illustrate these challenges with several examples from a qualitative study of the integration of electronic health records between hospital and ambulatory practices.
\end{abstract}

\section{Introduction}

Healthcare coordination is critically important, but so far it has proven to be an elusive goal. The 2010 U.S. Affordable Care Act encouraged care coordination with financial incentives for new technology such as electronic health records, new organizational structures such as accountable care organizations, and new payment mechanisms such as value based or bundled payments. But even with the introduction of these tools and mechanisms, care coordination remains a problem today $[1,2]$.

Care coordination is defined as:

the deliberate organization of patient care activities between two or more participants involved in a patient's care to facilitate the appropriate delivery of health care services. Organizing care involves the marshaling of personnel and other resources needed to carry out all required patient care activities and is often managed by the exchange of information among participants responsible for different aspects of care. [3].

In most industries today, information technology has led to improved coordination by facilitating information sharing and exchange. In healthcare, new coordination technologies such as electronic health records, health information exchange, mobile health, and virtual medicine have been implemented, yet coordination remains difficult to achieve.

A landmark 1999 Institute of Medicine (IOM) report established lack of care coordination as a costly problem in the U.S. [4]. Subsequent studies reported that the consequences might be more severe than the IOM's original assessment. A 2010 federal report projected that 15,000 Medicare patients every month suffered such serious harm in the hospital that it contributed to their deaths [4]. And this is not just a U.S. issue: medical errors, and lack of coordination were found to be pervasive in five highly industrialized countries, including Australia, Canada, New Zealand, the UK, and the U.S [5].

There is general consensus among those who study healthcare delivery that current systems are highly fragmented and suffer from a lack of coordination and communication, and in many cases, a lack of knowledge on how clinical and patient processes should be defined, organized, and managed to achieve costeffective and timely access to appropriate care. [6]

Why is this still the case today? Other industries have been able to improve coordination through the use of technology. Businesses have recognized the importance of reengineering business processes, creating new organizational structures and training people to support IT enabled coordination. Why has the healthcare industry lagged other industries? While this industry has been slow to adopt new coordination technologies, we suggest that it has also lagged other industries in its inability to align processes, people, and organizational structures to support IT enabled care coordination. We suggest that care coordination requires the highest level of interdependence, in which inputs and outputs from different units are fully shared through mutual adjustments. This type of coordination is challenged by several characteristics of the healthcare industry including its organizational structure that has not integrated across the full care cycle, payment structure and regulation, professional control, failure impact and privacy, and information granularity. We suggest that information technologies alone are insufficient; they must be aligned with new processes, organizational structures, and skills to 
improve care coordination. We provide some examples from a qualitative research study of the challenges associated with implementing one collaborative technology. Specifically, we focus on the integration of electronic health records between hospitals and ambulatory practices.

\section{Coordination theory and healthcare}

Coordination theory suggests that there are three types of interdependence and three corresponding types of coordination as defined in Table 1 [7]. There are very real costs involved in coordination, as these three types of coordination place increasingly heavy burdens on communication and decisions. Lower levels of interdependence such as "pooled" mean that units can work independently, and have little need for interaction, consultation, or exchange [8]. However, higher levels of interdependence such as "reciprocal" require more information sharing.

Table 1. Types of interdependence

\begin{tabular}{|l|l|l|l|l|}
\hline Type & Definition & $\begin{array}{l}\text { Coordination } \\
\text { Mechanism }\end{array}$ & $\begin{array}{l}\text { Application } \\
\text { to } \\
\text { Healthcare }\end{array}$ & $\begin{array}{l}\text { Business } \\
\text { IT } \\
\text { Examples }\end{array}$ \\
\hline Pooled & $\begin{array}{l}\text { Each part } \\
\text { renders a } \\
\text { discrete } \\
\text { contribution } \\
\text { to the whole }\end{array}$ & $\begin{array}{l}\text { Standardiza- } \\
\text { tion }\end{array}$ & $\begin{array}{l}\text { Care } \\
\text { monitoring }\end{array}$ & Extranets \\
\hline $\begin{array}{l}\text { Sequen- } \\
\text { tial }\end{array}$ & $\begin{array}{l}\text { Output of } \\
\text { one unit is } \\
\text { required by } \\
\text { another unit } \\
\text { in a serial, } \\
\text { non- } \\
\text { symmetrical } \\
\text { form }\end{array}$ & $\begin{array}{l}\text { Plan- } \\
\text { establishing } \\
\text { schedules by } \\
\text { which } \\
\text { actions are } \\
\text { governed }\end{array}$ & $\begin{array}{l}\text { Care } \\
\text { provision }\end{array}$ & $\begin{array}{l}\text { Electronic } \\
\text { data } \\
\text { interchange }\end{array}$ \\
\hline $\begin{array}{l}\text { Recipro- } \\
\text { cal }\end{array}$ & $\begin{array}{l}\text { Outputs of } \\
\text { each unit } \\
\text { become } \\
\text { inputs to } \\
\text { others }\end{array}$ & $\begin{array}{l}\text { Mutual } \\
\text { adjustment }\end{array}$ & $\begin{array}{l}\text { Care } \\
\text { coordination }\end{array}$ & $\begin{array}{l}\text { Resterprise } \\
\text { Resource } \\
\text { Planning } \\
\text { with shared } \\
\text { databases }\end{array}$ \\
\hline
\end{tabular}

In the provision of healthcare services, care can be monitored via standardization for pooled interdependence. For example, through standard reporting mechanisms, quality measures can be captured and compared. Care provision can be coordinated by plan for sequential interdependence. For example, providing laboratory results to a provider who can then decide on appropriate care is an example of sequential interdependence that is coordinated by plan. However, true care coordination requires mutual adjustment, involving a very high level of knowledge sharing so that multiple providers can work together to improve health outcomes. This is particularly important because of the risks and hazards embedded within both the healthcare structure and the care processes that affect patient safety [9].

Information technology has helped reduce the cost of coordination [10,11]. Businesses have adopted a variety of information tools that support different types of coordination. Some examples are shown in Table 1. Internally reciprocal interdependence has been achieved with ERP systems using shared databases that support reengineered processes. However, achieving reciprocal interdependence externally with partners in supply chains has been more challenging. If businesses continue to utilize proprietary systems that do not provide access to their supply chain partners, their level of interdependence is reduced. While information systems can support coordination by mutual adjustment, the organizations generally must also develop new processes and retrain people to support this type of coordination. Collaborative systems are only successful if organizations align their goals and develop processes and skills to share information appropriately. They must agree to joint problem solving and decision making, which requires a high level of knowledge sharing and communication. For example, successful implementation of collaborative planning, forecasting, and replenishment systems required coordinated changes to the organizational structure and business processes of both partners as well as the development of new skills [12]. Bounded rationality between firms (even if cooperation incentives are aligned) and a consequent lack of shared understanding of mutual interdependencies are major detriments to executing cooperative work among different organizations [13].

Since healthcare often requires coordination of multiple independent organizations, reciprocal coordination can also be more difficult to achieve, because it requires greater shared understanding and agreement. The structure of healthcare creates specific challenges that make reciprocal interdependence or coordination by mutual adjustment even more difficult.

\section{Challenges to coordination in healthcare}

Healthcare has a different social and technical context compared to traditional industries in which much IS research, including the role of coordination technology, has been conducted [14]. For a complete discussion of unique differences in healthcare, see [15]. We focus here on the challenges to coordination created by these differences.

\subsection{Integrating information across care cycles}


Medical care has traditionally been structured around medical specialties and discrete services, not the integrated care of medical conditions [16]. Competition traditionally takes place at the level of discrete interventions or services rather than addressing medical conditions over the full cycle of care. As a result, information has traditionally been siloed and not shared across providers involved in the total care delivery value chain. The care cycle includes preventing, diagnosing, preparing, intervening, recovering/ rehabilitating, and monitoring [16]. Providers have not been integrated across the entire care cycle. Information sharing across providers/competitors is necessary to treat patients whereas information sharing between partners/competitors in supply chains in other industries does not impact consumer welfare (only the division of consumer and producer surplus).

\subsection{Payment structure and regulation}

The healthcare industry separates financing from healthcare provision. The U.S. government and private insurance firms are typically the payers of healthcare, and often regulate payment terms. Thus, healthcare has an additional layer of required coordination compared to most other industries, where the customer who receives the product or service pays directly. This leads to additional coordination complexities.

The reimbursement system is the primary mechanism for regulation in the U.S. There are numerous regulations at all levels of government and these regulations lack coordination. In fact, some regulations constrain coordination, for example, by creating payments mechanisms that do not support email consultations.

New forms of competition such as accountable care organizations (ACOs) are an attempt to change payment mechanisms. But information sharing remains a challenge. Lack of integrated systems and fragmentation of third party health IT applications for population health management hamper ACOs. But technology alone is insufficient; ACOs also require more care managers and patient centered medical homes [17]. New processes, organizational structures, and personnel can be challenging to create.

\subsection{Personnel: professional control, information asymmetry, and scarcity}

The healthcare industry has traditionally been organized around the "profession" as the source of control, rather than market or bureaucratic control [18], although this is changing [19]. Traditionally, the health industry has relied on doctors and nurses who have very specialized knowledge gained through extensive training. Physicians, in particular, have been central to resource allocation and care processes in hospitals but have traditionally been independent of hospital management, although this is changing as more health networks are purchasing physician practices.

Integrating physicians more tightly into process improvement efforts is made difficult by the sociology of the medical professional and also by legal doctrines that have historically supported arms-length physician-hospital relationships. [20]

Coordination is challenged by physician autonomy [21] and a skepticism and lack of trust in information provided by others with different training [22]. Consequently, even physicians who are employed within an integrated network face challenges in coordinating care across the continuum.

There is a large knowledge differential among stakeholders in the healthcare industry, particularly between patients and providers. Only 12 percent of U.S. adults have sufficient health literacy to understand and use health information effectively and more than a third of adults are in the basic or below basic groups [23]. Since patients are unable to analyze and interpret the same type of information as providers, open access to shared information is insufficient. New processes and personnel such as care managers are required to translate information for the patients, along with new technologies such as personal health records.

While coordination has introduced a need for a new skill, coordination care management, there is a projected shortage of traditional healthcare providers [24-26]. The significant training requirements for these employees, coupled with reliance on federally funded residency positions for training physicians, exacerbate the pressures for increasing supply. Since we cannot quickly add more physicians and highly educated nurses, this industry is beginning to develop a cadre of physician extenders including nurse practitioners and physician assistants, who are expected to increase their provision of primary care services from 23 to 28 percent between 2010 and 2020 [25]. While this will decrease the deficit in supply, at the same time it also further increases the need for additional coordination mechanisms.

\subsection{Failure impact and privacy}

IT failure in healthcare typically has a much higher impact than in other industries, leading to the possibility of loss of life or decreased quality of life. In most other industries, the primary risk is financial; with IT value measured as economic impact [27]. This higher failure risk can contribute to a greater lack of trust or reliance on data that are shared within a system. There is a significant cost of poor information 
and reliance on potentially incorrect information. Thus, even if collaborative systems provide shared data, providers may be skeptical about relying on data that others have provided.

Additionally, there is significant concern regarding information privacy, since health information is highly personal [28] and individuals are very emotional regarding use of their medical history [29]. Data sharing is challenged by these concerns, and remains a major barrier to national health information exchange. New processes may be required to address these issues.

\subsection{Information granularity}

Care information differs in its granularity within different parts of the care delivery value chain. In the hospital, data are often monitored minute by minute (for example, recording heart rate or oxygen levels over time). However, in ambulatory practices, data are tracked at the time of the visit, which can be monthly or yearly. Today, we lack standards for translating critical episodic flow data into transactional lifetime records. Additionally, there is a debate regarding text based context and discrete data. While the latter are most useful for analytics and quality reporting, many medical professionals feel that rich context is lost with discrete data. A major question is how to balance the needs for both context rich and discrete data.

\section{Coordination facilitators}

Most businesses have found that IT alone does not support collaboration; it must be aligned with processes, organizational structures, and coordinators. While the same is true for healthcare, the fundamental uniqueness of the healthcare industry makes this alignment more difficult. Figure 1 shows the required alignment of coordination IT with the other facilitators, with a summary of the major challenges within healthcare.

Figure 1. Key challenges to aligning information technology in healthcare

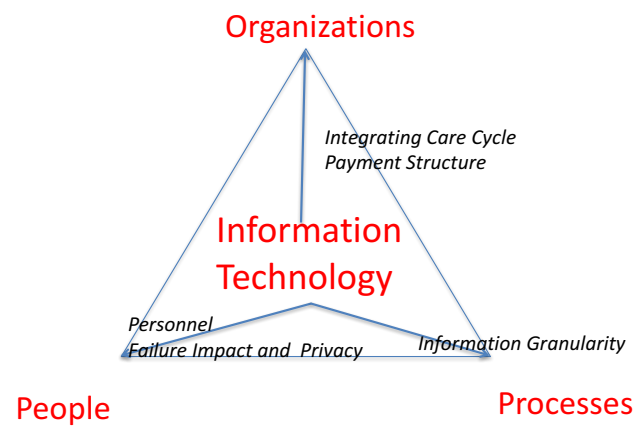

\subsection{Information Technology}

Technology is one of the major facilitators of coordination. Most industries have coordinated activities with technology that supports all three levels of interdependence. In healthcare, however, coordination by standardization and mutual adjustment are insufficient for care coordination. They can support care monitoring and provision, but for care coordination, reciprocal interdependence is required due to the complex high failure risk environment. Care coordination requires mutual adjustment in which both outputs and inputs are completely shared. But this is challenging in healthcare due to its organizational structure requiring changes by multiple often independent units and highly trained professionals, its information asymmetry and dissimilar granularity, and high failure impact and privacy concerns.

\subsection{People}

Another mechanism to facilitate coordination is people. The complexity of healthcare, information asymmetry, and scarcity of professionals necessitates participation of multiple care providers. Effective healthcare teamwork requires numerous competencies [30] to reduce risk and hazards and ensure patient safety $[9,31]$.

The current organizational structure of medical care means that there are multiple points of transition among units whose incentives may not be aligned. During points of transition, when information about or accountability/responsibility for some aspect of a patient's care is transferred between two or more health care entities, information and responsibility should be transferred together [3]. But traditionally, these transition points have contributed to worse health outcomes [32-34].

The uniqueness of the healthcare industry in terms of the nature of the providers, with high professional control, scarcity, and knowledge differentials also contributes to the difficulty of aligning technology with people. The professionals may balk at dependence upon a system and may be skeptical about the information within the system, especially if that professional did not create/enter the information, particularly given the high failure risk in healthcare. The technology must accommodate information asymmetry by incorporating translators of complex information, such as care managers, and the scarcity of traditional providers adds a need for a technology to further coordinate efforts with new physician extenders. 


\subsection{Processes}

A third mechanism that facilitates coordination is the revision of work processes so that they are focused more on coordinated processes. This was the fundamental change that adoption of ERP systems drove, a reengineering of work from a functional perspective to a business process perspective. But change in healthcare processes has occurred much more slowly. Due to the complex organizational structure, there has traditionally been minimal communication or coordination between multiple entities, resulting in unavailable medical information at the time of treatment, replication of test results, protocols not followed, prescription of contraindicated procedures or medications, with poor clinical outcomes and unnecessary costs [35]. One problem is that different care facilities focus on information with different levels of granularity, for example episodic versus lifetime care, challenging information transmission. The payment structure adds a complexity of documentation processes that are not directly tied to care delivery that must be coordinated as well. The autonomous professionals, the physicians, who have wielded much control in the past, have also slowed process change.

\subsection{Organization}

"When software is implemented in complex, established health systems the power of the existing organizational structures and processes will force the records system to conform itself to them." [36] The competitive organizational structure and the payment structure in healthcare have driven the development of systems such as EHRs, mobile health, and telemedicine that support structures that are complex and siloed. Sharing of information is confounded via privacy concerns. Thus, while the technology is aligned with the organizational structures, it is not aligned with care coordination. The ACO model is an attempt to change payment structures, but this will require new forms of technology.

\section{Research site and methodology}

We will provide some examples of the alignment challenges from a study of one coordination technology, integrated electronic health records that were implemented at the Lehigh Valley Health Network (LVHN) in all physician practices within that network, as well as the hospital system. We focus on the coordination of care between $\mathrm{OB} / \mathrm{GYN}$ practices and the triage unit at the hospital, where pregnant women go if they think that they are in labor or have pregnancy related problems. Some patients are seen at triage and released; others are admitted to the Labor and Delivery unit.

Prior to the implementation of the new electronic health record system (EHR), some of the ambulatory practices used a paper system; others a different EHR system. Furthermore, pregnant women could show up at triage for treatment, and the records supplied by the offices to triage might be unavailable or out of date. Triage records were also unavailable in the office when the patient returned there for treatment following their hospital visit. After the implementation of this coordination technology, data from the office EHR was transmitted directly to the triage unit and data from the triage EHR populated the electronic office record used in the ambulatory practice.

We conducted a qualitative study of the challenges associated with the introduction and integration of EHRs. We completed 76 one-hour interviews with both clinical and non-clinical staff over a three-year time period. For a detailed overview and details of this study, see [37]. We use this study to provide examples of the challenges of aligning information technology within the healthcare industry.

\section{Examples of coordination and alignment challenges}

In our study, we found that pooled or sequential interdependence were sufficient for documenting data and making records available in multiple locations, but they were insufficient for coordinated care. The requirement to capture specific information for quality reporting meant that standard fields and codes were necessary, which supported pooled interdependence. In order for the records to be available at another location, they had to be signed off, which required sequential coordination mechanisms. But for true coordinated care, the physicians had to use reciprocal coordination, inputting and retrieving data from within the system. To achieve care coordination, they needed a complete picture of a patient, which required not only the ability to input data to the electronic record, but easy retrieval of information from multiple providers in different locations. Coordinated care did not occur until data flowed from the ambulatory record to triage and then from the triage unit back into the office record. And care was not coordinated until the providers learned not only how to input data, but also how to retrieve data. One provider noted that previously when they wanted to send a message to the next provider, they would use a "flag mechanism." But with all the data now captured within the system, 
as the users became proficient in data retrieval, they could depend upon their notes being available to other providers, and they would not have to use a separate communication mechanism. But alignment issues between the system and existing processes, people, and organizational structures challenged reciprocal coordination. We provide some examples below.

\subsection{Aligning information technology with processes}

We found that a key challenge to coordination between IT and processes was the difference in information granularity between the ambulatory and hospital practices. When the two systems were initially integrated, we found that data were initially lost due to a mismatch in the information granularity. Data in the triage unit were recorded in minutes, while data in the office system were recorded in days. When data were transmitted from triage to the office, the detailed information was initially lost or overridden because there were no fields to record data at the same level of granularity. This problem challenged both sequential and reciprocal interdependence since the discrete data from triage could not be accessed in the office or could be incorrectly reported. In order to effectively use the shared information, the health network had to create a work-around so that after a patient was seen in triage, a color code was added to the ambulatory EHR to alert the office physicians to go to a newly created screen that reported information from triage with smaller granularity. This enabled the office providers to use the information from triage as they provided office care, an example of sequential interdependence using coordination by plan to provide follow up care at the next visit. And for care coordination, this information was now available to all providers so that they could coordinate using mutual adjustment for reciprocal interdependence. This information remained within the EHR and could be retrieved for all follow up care, whether in the office or subsequent triage visits, or even for other care providers besides the obstetrics providers.

In addition, we also found that the system was more readily used when it supported standard workflow processes. For example, we found that data that were transmitted from the office EHR directly into the triage unit were used infrequently because accessing these data was not within the care team's workflow processes within triage. Very few individuals even knew where to look to find this data. Instead, providers relied on accessing the original office records in triage instead of using the triage system for historical information. However, when data flowed back to the office, it flowed directly into the portions of the office record that were within the standard workflow practice, and therefore the information was more useful for care coordination. But implementing standard work processes was a challenge, as one physician noted, "It seems we have come to agreement on standardization, but the stumbling block is just finding ways to get it implemented." Implementation of new processes was exacerbated by the people challenges discussed below.

\subsection{Aligning information technology with people}

The coordination technologies today challenge the professional control of the physicians, who have traditionally been fairly independent in their practices. In addition, due to the high failure impact, there can be a lack of trust in the information, thus making the shared system less helpful in coordinating care.

Many of the physicians initially felt that the EHR system did not support the way that they worked. Documentation had traditionally been the responsibility of the individual physicians and they each had completed this process in their own way prior to this implementation. One doctor noted, "I may do things one way, but somebody else may do things a different way...If they have like 12 visits in a pregnancy, 12 people could touch that chart. And people are probably using the chart differently." The new EHR required them to document in a specific way so that others could find the information, enabling both sequential and reciprocal coordination. Many were concerned that documentation detracted from their processes, particularly in maintaining eye contact with their patients. Implementing process change was difficult, as some providers felt that "they're taking away the autonomy piece...People don't want to look at that standardization... They can't see the value of it." "We're taught to be skeptical and not believe things that are there and then when you sort of have different mindsets about what the goal of the medical record really is, that part's hard."

To achieve reciprocal coordination, providers not only had to learn how to input data but also to retrieve data provided by others. Information retrieval was challenging when providers documented differently because the providers did not know where to look for the information. The providers initially found it difficult to find information, some commenting that their jobs had now been altered to require them to be data miners. Many felt that they had not been trained to do this adequately and that it was difficult to do this within the system, particularly when individuals could document the same information in different places. 
There was also concern that the new EHR, with its discrete fields, did not facilitate the capture of the nuances of the "patient's story," and thus was not as useful. One provider commented, "So now there's a series of checked boxes, in an attempt to really standardize the way things are documented. But the series of check marks don't tell the same kind of story. They just don't." The perceived necessity of completing both discrete fields and free text added to their burden.

Many of the providers did not trust data that was submitted by others into the EHR, challenging reciprocal coordination. Even when test results were put directly within the record and viewed within the flow of the work process, providers commented that they still went back to the source documents (e.g. lab reports) to verify the information in their EHRs due to the high failure risk. Likewise, the residents in the triage unit were held to a high standard in terms of data verification, and were taught to look at the source reports to make sure that they did not miss anything. Several physicians noted that if someone else wrote in their report that they actually reviewed a source report and were commenting on that report, they would tend to trust that information more than if someone just commented without specifically stating that they saw the source.

While the system supports patient interaction, not all data and notes were provided to the patient, due to the knowledge differential. Even within the system, as more data were entered by very different specialties, information asymmetry, even among the physicians, created some challenges for making the system useful for reciprocal coordination. For example, the original problem lists that were transferred to the hospital from the office records contained every problem recorded by every physician in any specialty who previously saw that patient. This made the information unwieldy, resulting in information overload that detracted from the use of the system for information retrieval and coordination of care. As a result, new processes for OB physicians and system enhancements were created to narrow down the list to pregnancy relevant problems so that only this subset was transferred to triage.

\subsection{Aligning information technology with organizations}

The information technologies that have been implemented today reflect the fragmented system of healthcare due to lack of information sharing among multiple providers involved in the full care cycle and they are driven by the payment structure. Privacy concerns make it difficult to share information among competitive institutions involved in the complete care of an individual.

In our study, we focused primarily on a single health network. Thus, our primary focus was not on how organizational structure affects alignment. We did, however, find one example of a problem created by the lack of information sharing among competitive providers because sometimes patients were seen in triage from outside the health network. In these cases, historical information was unavailable since there was no sharing of records between health networks, making it difficult to coordinate care for out of network participants. This limited sequential coordination since historical information from out of the network was unavailable in triage. It also limited reciprocal coordination because information on the care provided was not immediately available to the out of network providers, challenging coordinated care.

Additionally, most physicians feel that the design of most electronic health record systems is driven by the payment system. One provider commented, "It's not very physician friendly. It's very billing friendly." Attention to appropriate billing codes was raised as a concern because the physicians found that that activity distracting from actual patient care. They felt that they were spending too much time searching for correct billing codes. Previously, coders often added billing codes after the visit. But the electronic health record systems require the physician to enter the code prior to completion of the record for that visit. Providers felt that this search time could better be allocated to care, improving reciprocal care coordination.

\section{Conclusions}

Most businesses have successfully aligned their coordination technologies with new business practices, reengineered their business processes, and retrained individuals to work more collaboratively. Healthcare has lagged business. We suggest that this is due to several unique challenges in healthcare including its requirement for information sharing among providers across the entire care cycle, payment structure, tradition of control by independent professionals with high knowledge differential who are in short supply, information granularity differences, and high failure risk and privacy concerns. These will continue to challenge the use of coordination technology unless the technologies can be introduced along with changes in the organizational structures, work processes, and people skills.

This is particularly the case because reciprocal interdependence, the highest level of interdependence, is required for care coordination. Lower levels of interdependence, such as pooled and sequential, can 
assist in monitoring care quality and the provision of healthcare. But coordination of care requires a high level of knowledge sharing and coordination by mutual adjustment. These adjustments are challenged by the current organizational and professional structure of the healthcare industry, along with information asymmetry, information granularity differences, and high risk/privacy concerns.

Future research should focus on the combination of characteristics that can most effectively align with information technology, so that we create systems that can have the most value for care coordination. For example, we should understand the characteristics of new collaborative forms of healthcare delivery, such as accountable care organizations. We should also consider what processes will need to be reengineered, what types of personnel skills will be needed, and work with health care providers to create the information technologies that will support these types of collaborative efforts. We need to consider how some of the challenges such as privacy risk and payment mechanisms affect the types of technology that will be most effective. We need to develop mechanisms to create trust in shared data. As IS researchers, we should be working with health care providers to ensure that the systems that are developed can be used to achieve care coordination by understanding the needs and challenges for coordination in this industry. We cannot assume that the systems alone will drive coordination. Coordination will only occur if organizational structures, processes, and skills change to work in conjunction with new technologies.

\section{References}

1. Jones C, Vu M, O'Donnell M, Patel S, Wald H, Coleman E, DeWalt D. A failure to communicate: a qualitative exploration of care coordination between hospitalists and primary care providers around patient hospitalization. Journal of General Internal Medicine. 2015;30(4):417-24.

2. Commonwealth Fund. All nations face challenges coordinating care 2015 [June 7, 2015]. Available from: http://www.commonwealthfund.org/interactives-anddata/infographics/2015/dec/all-nations-face-challengescoordinating-care.

3. McDonald K, Schultz E, Albin L, Pineda N, Lonhart J, Sundaram V, Smith-Spangler C, Brustrom J, Malcolm E, Rohn L, Davies S. Care coordination measures atlas update Washington2014 [June 6, 2015]. 14-0037-EF]. Available from:

http://www.ahrq.gov/professionals/prevention-chroniccare/improve/coordination/atlas2014/chapter2.html.

$4 . \quad$ Rabin R. Health care's "dirty little secret": no one may be coordinating care. Washington Post. 2013.

5. Commonwealth Fund. Medical errors, lack of coordination, and poor physician-patient communication are pervasive in health systems of five nations 2013 [June 6, 2016]. Available from: http://www.commonwealthfund.org/publications/pressreleases/2003/may/medical-errors--lack-of-coordination-and-poor-physician-patient-communication-are-pervasive-inheal.

6. Green L. The vital role of operations analysis in improving healthcare delivery. Manufacturing and Service Operations Management. 2012;14(4):488-94.

7. Thompson JD. Organizations in action; social science bases of administrative theory. New York: McGraw Hill; 1967.

8. Daft R. Organization Theory and Design. 7 ed. Cincinatti, Ohio: Southwestern College Publishing; 2001.

9. Donabedian A. Explorations in quality assessment and monitoring; the definition of quality and approaches to its assesment. Ann Arbor, MI: Health Administration Press; 1980 .

10. Shin N. Does information technology improve coordination? an empirical analysis. Logistics Information Management. 1999;12(1/2):138-44.

11. Malone T, Rockart J. Computers, networks, and the corporation. Scientific American. 1991;265(3):92-9.

12. Cederlund J, Kohli R, Sherer SA, Yao Y. How Motorola put CPFR into action. Supply Chain Management Review. 2007;11(7):28-35.

13. Gulati R, Lawrence P, Puranam P. Adaptation in vertical relationships: beyond incentive conflict. Strategic Management Journal. 2005;26(5):415-40.

14. Chiasson M, Davidson E. Pushing the contextual envelope: developing and diffusing IS theory for health information systems research. Information \& Management. 2004; $14: 155-88$

15. Sherer SA. Advocating for action design research on IT value creation in healthcare. Journal of Association for Information Systems. 2014;15(12).

16. Porter M, Teisberg E. Redefining Health Care. Boston, Mass: Harvard Business School Press; 2006.

17. Terry K. Accountable care organizatons struggle with health IT infrastructure. Informationweek. 2012 November 19, 2012.

18. Freidson E. Professionalism: The Third Logic. Chicago: University of Chicago Press; 2001.

19. Currie WL, Guah MW. Conflicting institutional logics: a national programme for IT in the organisational field of healthcare. Journal of Information Technology. 2007;22(3):235-47.

20. Randall C, Rebitzer J, Taylor V. Organizational fragmentation and care quality in the U.S. healthcare system. Journal of Economic Perspectives. 2008;22(4):93-113.

21. Kohli R, Kettinger W. Informating the clan: controlling physicians' costs and outcomes. MIS Quarterly. 2004;28(3):363.

22. Terrizzi S, Sherer S, Meyerhoefer C, Sheinberg M, Levick D. Extending the technology acceptance model in healthcare: identifying the role of trust and shared information. AMCIS 2012 Proceedings 2012.

23. Koh HK, Berwick DM, Clancy CM, Baur C, Brach C, Harris L, Zerhusen G. New federal policy initiatives to boost health literacy can help the nation move beyond the 
cycle of costly "crisis care". Health Affiars. 2012;31(2):4340443.

24. Sataline S, Wang S. Medical schools can't keep up. Wall Street Journal. 2010 April 12, 2010.

25. Health Resources and Services Administration. Projecting the supply and demand for primary care practitioners through 2020 2013. Available from: http://bhpr.hrsa.gov/healthworkforce/supplydemand/usworkf orce/primarycare/.

$26 . \quad$ American Association of Colleges of Nursing. Nursing Shortage 2012 [updated August 6, 2012]. Available from: $\quad$ http://www.aacn.nche.edu/media-relations/factsheets/nursing-shortage.

27. Kohli R, Grover V. Business value of IT: an essay on expanding research directions to keep up with the times. Journal of the Association for Information Systems. 2008;9(1):23.

28. Fichman R, Kohli R, Krishnan R. The role of information systems in healthcare: current research and future trends. Information Systems Research. 2011;22(3):419-28.

29. Anderson C, Agarwal R. The digitization of healthcare: boundary risks, emotion, and consumer willingess to disclose personal health information. Information Systems Research. 2011;22(3):469-90.

30. Agency for Healthcare Research and Quality. Medical teamwork and patient safety: the evidence based relation Rockville, MD 2005 [June 14, 2015]. Available from: $\quad$ http://archive.ahrq.gov/research/findings/finalreports/medteam/index.html.
31. Coyle YM, Battles JB. Using antecedents of medical care to develop valid quality of care measures. $J$ Qual Health Care. 1999; Feb(1):5-11.

32. Moore C, Wisnievesky J, Williams S. Medical errors related to discontinuity of care fron an inpatient to an outpatient setting. $J$ General Internal Medicine. 2003;2003(18):646-51.

33. Kripalani S, LeFever F, Phillips C. Deficits in communication and information transfer between hospitalbased and primary care physicians: implications for patient safety and continuity of care. JAMA. 2007;297(8):831-41.

34. Debul R, Rebitzer J, Taylor L. Organizational fragmentation and care quality in the US healthcare system. $J$ Econom Perspectives 2008;22(4):93-113.

35. Institute of Medicine. Engineering a learning healthcare system. Healthcare Institute of Medicine and National Academy of Engineering US Rountable on Value and Science-Driven Healthcare, editor. Washington, DC: National Academies Press; 2011.

36. Christensen C, Grossman J, Hwang J. The Innovator's Prescription: A disruptive solution for health care. New York: McGraw Hill; 2009.

37. Sherer S, Meyerhoefer C, Sheinberg M, Levick D. Integrating commercial ambulatory electronic health records and hospital systems: an evolutionary process. International Journal of Medical Informatics. 2015;84(9):683-93. 